\title{
Tree rings and volcanic cooling
}

To the Editor - In their Letter, Mann and colleagues ${ }^{1}$ claim to have identified a discrepancy between the degree of volcanic cooling in climate model simulations and the analogous cooling indicated in a tree-ring-based Northern Hemisphere temperature reconstruction ${ }^{2}$, and attribute it to a putative temporary cessation of tree growth at some sites near the temperature limit for growth. They argue that this growth cessation would lead to missing rings in cool years, thus resulting in underestimation of cooling in the tree-ring record. This suggestion implies that periods of volcanic cooling could result in widespread chronological errors in tree-ring-based temperature reconstructions ${ }^{1,3}$. Mann and colleagues base their conclusions solely on the evidence of a tree-ring-growth model.
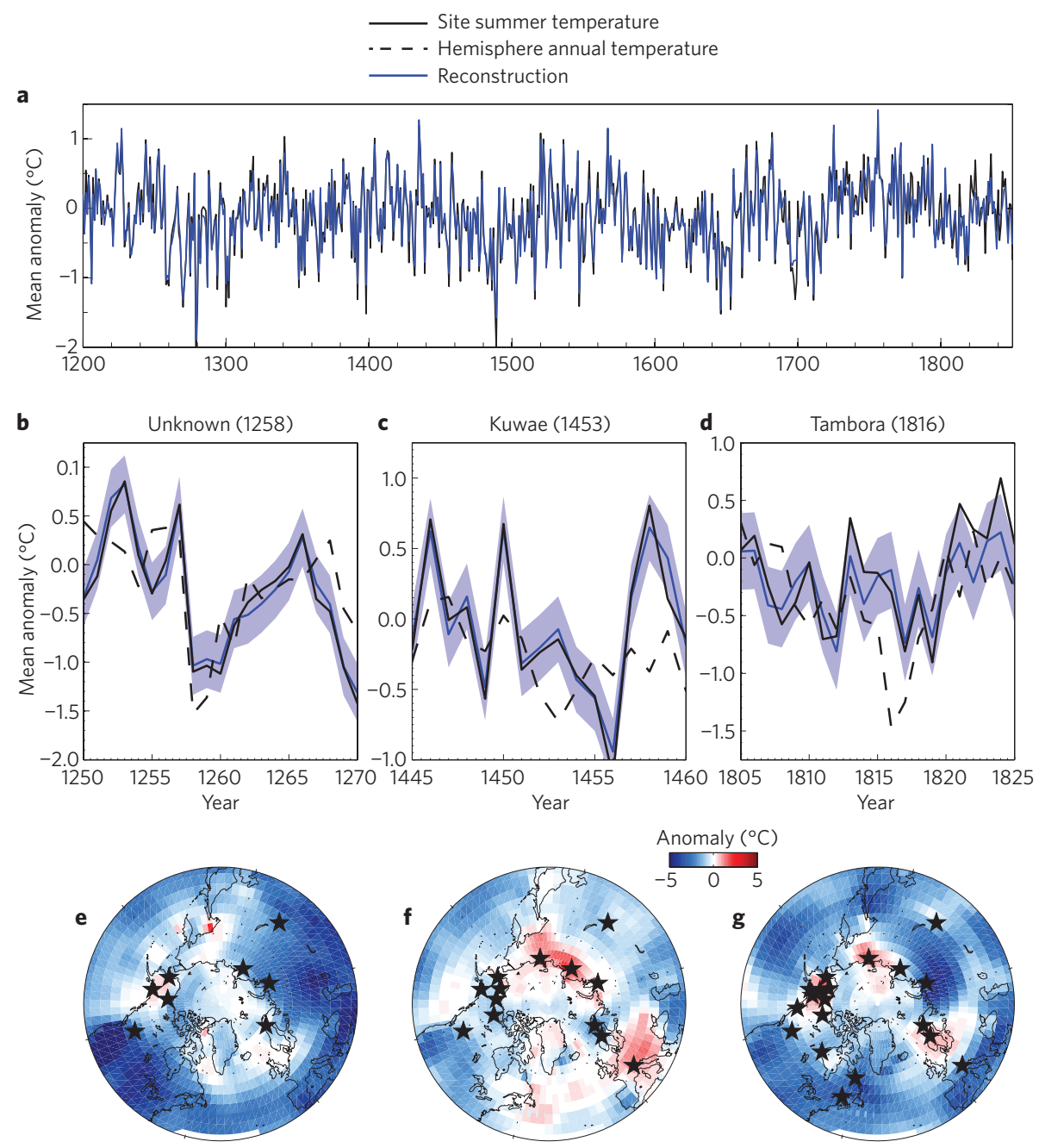

Figure 1 | Simulated response of tree-ring growth to Northern Hemisphere temperature. We used a forward growth model ${ }^{5}$ to create a pseudoproxy network for climate variations over the past 800 years (a), and show it agrees well with the simulated summer temperatures, even over specific volcanic intervals (b-d) highlighted by Mann etal. ${ }^{1}$ The distribution of sites $^{2}$ (shown by stars in $\mathbf{e}-\mathbf{g}$ ) and the pattern of temperature anomalies ${ }^{13}$ together determine the reconstruction for those years $(\mathbf{e}-\mathbf{g})$. For comparison with Mann etal. ${ }^{1}$, the dashed black line shows the CSM1.4 complete Northern Hemisphere annual mean temperature anomaly. Blue shading indicates uncertainty around the reconstruction based on the reduction of error statistic. See Supplementary Information for additional methods.

Here we point to several factors that challenge this hypothesis of missing tree rings; specifically, we highlight problems in their implementation of the tree-ring model used $^{1}$, a lack of consideration of uncertainty in the amplitude and spatial pattern of volcanic forcing and associated climate responses, and a lack of any empirical evidence for misdating of treering chronologies.

Several aspects of their tree-ringgrowth simulations are erroneous. First, they use an algorithm that has not been tested for its ability to reflect actual observations (Supplementary Fig. 1), even though established growth models, such as the Vaganov-Shashkin model ${ }^{4,5}$, are available. They rely on a minimum growth temperature threshold of $10{ }^{\circ} \mathrm{C}$ that is incompatible with real-world observations. This condition is rarely met in regions near the limit of tree growth, where ring formation demonstrably occurs well below this temperature: there is abundant empirical evidence that the temperature limit for tree-ring formation is around $5{ }^{\circ} \mathrm{C}$ (refs 6,7). Mann and colleagues arbitrarily and without justification require 26 days with temperatures above their unrealistic threshold for ring formation. Their resulting growing season becomes unusually short, at 50-60 days rather than the more commonly observed 70-137 days ${ }^{4,7}$. Furthermore, they use a quadratic function to describe growth that has no basis in observation or theory, and they ignore any daylength and moisture constraints on growth. These assumptions all bias Mann and colleagues' tree-growth model results ${ }^{1}$ towards erroneously producing missing tree rings.

Reconstructing simulated temperatures in the same manner as Mann and colleagues, but using a well-tested tree-ring growth model ${ }^{5}$ and realistic parameters provides no support for their hypothesis (Fig. 1). Instead we find good agreement between summertime temperatures reconstructed from pseudoproxies and those simulated with a climate model $(\mathrm{CSM} 1.4)^{8}$ (Fig. 1a), for the whole record as well as in specific years following major volcanic eruptions (Fig. 1b-d). Mann and colleagues' principal result arises from their failure to select a realistic minimum temperature for growth, use actual treering chronology locations and recognize 
that the simulated climate response to eruptions varies geographically (Fig. 1e-g).

Furthermore, the timing and magnitude of cooling in climate model simulations is uncertain. Simulations of the AD 1258 / 1259 eruption with an Earth system model ${ }^{9}$ place estimates of the maximum Northern Hemisphere summer cooling between 0.6 and $2{ }^{\circ} \mathrm{C}$. This range exceeds the uncertainty range used in Mann and colleagues' comparison with tree-ring reconstructions, and would be even wider if additional error sources (for example, the size distribution of volcanic particulates, the location of the volcano and the season of eruption) were taken into account ${ }^{10}$. An alternative hypothesis of an overestimation of volcanically induced cooling in the simulations cannot be ruled out.

The ring-width-based temperature reconstruction for the Northern Hemisphere $^{2}$ does show muted cooling coincident with volcanic eruptions (Supplementary Fig. 2). This response, in part, is related to the spatial distribution of the observing network and to the lagged effects of prior-year weather on subsequent ring formation ${ }^{11}$. An independently produced circum-boreal tree-ring network of 383 maximum latewood density chronologies - a parameter measured from samples cross-dated using ring-width data, and one that is more immediately responsive to abrupt summer temperature changes $^{12}$ - shows precise correspondence with the timing of explosive volcanic eruptions (Supplementary Fig. 2). There is no evidence whatsoever of chronological errors or 'smearing' back to 1400, nor do Mann and colleagues present any. On the contrary, there is substantial evidence that independent boreal tree-ring data sets show multiple synchronous cooling events consistent with evidence of highly explosive volcanic eruptions, without significant chronological error, for the past two millennia ${ }^{13-15}$.

Limitations in the spatial coverage of trees, insufficient nineteenthcentury instrumental data for tree-ring calibration, differences in reconstruction methodologies, and the seasonality of tree growth can cause uncertainties in large-scale dendroclimatic temperature reconstructions, and hence in the quantification of the climatic consequences of volcanic eruptions. However, there is clear evidence that actual boreal treering chronologies are correctly dated and show large-scale, synchronous evidence of volcanically induced cooling ${ }^{14}$ (Supplementary Fig. 2). Efforts to estimate the sensitivity of the climate system to significant volcanic eruptions will be enhanced by parallel efforts to improve the coverage and interpretation of the palaeoobservational network, and prescribe radiative forcing of past volcanic events more accurately so that simulations of the radiative and dynamical responses of the climate system to external forcing can be improved.

References

1. Mann, M. E., Fuentes, J. D. \& Rutherford, S. Nature Geosci. 5, 202-205 (2012).

2. D’Arrigo, R., Wilson, R. \& Jacoby, G. J. Geophys. Res. 111, D03103 (2006).

3. Jansen, E. J. et al. in IPCC Climate Change 2007: The Physical Science Basis (eds Solomon, S. et al.) 433-497 (Cambridge Univ. Press, 2007).

4. Vaganov, E. A., Hughes, M. K. \& Shashkin, A. V. Growth Dynamics of Conifer Tree Rings: Images of Past and Future Environments (Springer, 2006).

5. Tolwinski-Ward, S. E., Evans, M. N., Hughes, M. K. \& Anchukaitis, K. J. Clim. Dynam. 36, 2419-2439 (2010).

6. Körner, Ch. Alpine Treelines (Springer, 2012).

7. Rossi, S., Deslauriers, A., Anfodillo, T. \& Carraro, V. Oecologia 152, 1-12 (2007)

8. Ammann, C. M., Joos, F., Schimel, D. S., Otto-Bliesner, B. L. \& Tomas, R. A. Proc. Natl Acad. Sci. USA 104, 3713-3718 (2007)

9. Timmreck, C. et al. Geophys. Res. Lett. 36, L21708 (2009).

10. Toohey, M., Krüger, K., Niemeier, U. \& Timmreck, C. Atmos. Chem. Phys. 11, 12351-12367 (2011).

11. Frank, D., Büntgen, U., Böhm, R., Maugeri, M. \& Esper, J. Quat. Sci. Rev. 26, 3298-3310 (2007).

12. Briffa, K. R., Jones, P. D., Schweingruber, F. H. \& Osborn, T. J. Nature 393, 450-455 (1998).

13. Larsen, L. B. et al. Geophys. Res. Lett. 35, L04708 (2008).

14. Breitenmoser, P. et al. Palaeogeogr. Palaeoclimatol. Palaeoecol. 313-314, 127-139 (2012).

15. Salzer, M. W. \& Hughes, M. K. Quat. Res. 67, 57-68 (2007).

Additional information

Supplementary information accompanies this paper on www.nature.com/naturegeoscience. The Northern Hemisphere tree-ring reconstructions shown in

Supplementary Fig. S2 are archived at the National Climate Data Centre: www.ncdc.noaa.gov/paleo/recons.html. The spatial reconstruction plots are available at the University of East Anglia, Climate Research Unit web server: http:// www.cru.uea.ac.uk/cru/people/briffa/temmaps/. The raw data and source code to perform our analysis and reproduce our figures can be found at www.ldeo.columbia. edu/ kja/access/volcanic2012.
Kevin J. Anchukaitis ${ }^{1,2}$, Petra Breitenmoser ${ }^{3}$, Keith R. Briffa ${ }^{4}$, Agata Buchwal ${ }^{5,6}$, Ulf Büntgen ${ }^{3,5}$, Edward R. Cook', Rosanne D. D'Arrigo', Jan Esper7, Michael N. Evans ${ }^{8}$, David Frank ${ }^{3,5}$, Håkan Grudd ${ }^{9}$, Björn E. Gunnarson ${ }^{9}$, Malcolm K. Hughes ${ }^{10}$, Alexander V. Kirdyanov"11, Christian Körner ${ }^{12}$, Paul J. Krusic ${ }^{9}$, Brian Luckman ${ }^{13}$, Thomas M. Melvin ${ }^{4}$, Matthew W. Salzer ${ }^{10}$, Alexander V. Shashkin"1, Claudia Timmreck ${ }^{14}$, Eugene A. Vaganov ${ }^{11,15}$ and Rob J.S. Wilson ${ }^{1,16 *}$

'Lamont Doherty Earth Observatory of Columbia University, Palisades, New York 10964, USA, ${ }^{2}$ Department of Geology and Geophysics, Woods Hole Oceanographic Institution, Woods Hole, Massachusetts 02543, USA, ${ }^{3}$ Oeschger Centre for Climate Change Research, University of Bern, 3012

Bern, Switzerland, ${ }^{4}$ Climatic Research Unit, School of Environmental Sciences, University of East Anglia, Norwich, NR4 7TJ UK, ${ }^{5}$ Swiss Federal Research Institute WSL, 8903 Birmensdorf, Switzerland, ${ }^{6}$ Institute of Geoecology and Geoinformation, Adam Mickiewicz University, 61-680 Poznan, Poland, ${ }^{7}$ Department of Geography, Johannes Gutenberg University, Becherweg 21, 55099 Mainz, Germany, ${ }^{8}$ Department of Geology and Earth System Science Interdisciplinary Center, University of Maryland, Maryland 20742, USA, ${ }^{9}$ Bert Bolin Centre for Climate Research, Department of Physical Geography and Quaternary Geology, Stockholm University, SE-106 91 Stockholm, Sweden, ${ }^{10}$ Laboratory of Tree-Ring Research, University of Arizona, Tucson, Arizona 87921, USA, ${ }^{11} \mathrm{~V}$. N. Sukachev Institute of Forest SB RAS, Akademgorodok, Krasnoyarsk 660036, Russia, ${ }^{12}$ Institute of Botany, University of Basel, $\mathrm{CH}-4056$ Basel, Switzerland, ${ }^{13}$ Department of Geography, University of Western Ontario, London, Ontario N6A 5C2, Canada, ${ }^{14}$ Max-Planck-Institut für Meteorologie, Bundesstrasse 53, D-20146 Hamburg, Germany, ${ }^{15}$ Institute of Forest and Siberian Federal University, Krasnoyarsk 660041, Russia, ${ }^{16}$ School of Geography and Geosciences, University of St Andrews, Fife, KY16 9AL, UK.

*e-mail: rjsw@st-andrews.ac.uk

Published online: 25 November 2012
Mann et al. reply - In our Letter, we offered a hypothesis to explain the absence of the expected volcanic cooling responses in tree-ring-based reconstructions of past hemispheric temperatures ${ }^{1}$. In their comment on our Letter, Anchukaitis et al. critique various aspects of our approach.
Although we welcome alternative hypotheses, we note that their comment does not provide a plausible alternative explanation for this vexing problem. And despite their claim, our analysis does not question the validity of large-scale treering-based reconstructions in general - in fact, we show that tree-ring reconstructions effectively capture long-term temperature trends. We have simply called into question the ability of tree-ring width proxies to detect the short-term cooling associated with the largest volcanic eruptions of the past millennium. 